\title{
Assessment of the role of computed tomography versus echocardiography in pulmonary hypertension
}

\author{
Ahmed Z.E. Abdelhafiz ${ }^{\mathrm{a}}$, Khaled A. Al Khashab ${ }^{\mathrm{b}}$, Assem F. Elessawy ${ }^{\mathrm{c}}$, \\ Radwa A. Elhefny ${ }^{\mathrm{c}}$, Fatmaalzahraa S. Abdalrazik ${ }^{\mathrm{d}}$
}

\begin{abstract}
Background The era of diagnosing pulmonary arterial hypertension is rapidly evolving. There are changes in the definition, screening, diagnostic modalities, and disease staging.
\end{abstract}

Aim This study aims to assess pulmonary hypertension using computed tomography (CT) and echocardiography.

Design This is a cross-sectional study.

Participants and methods This study included 30 cases diagnosed with pulmonary artery hypertension according to the inclusion and exclusion criteria. All patients were subjected to a careful assessment of history, a skillful clinical examination, and investigations: (a) complete blood picture, liver kidney functions, bleeding profile, and arterial blood gases. (b) Spirometry. (c) Echocardiogram. (d) CT chest.

Results The correlation between the ratio of main pulmonary artery and aorta to other study parameters was statistically significant. There was a negative statistically significant correlation between the $\mathrm{mP} / \mathrm{Ao}$ ratio and oxygen saturation $(P=0.001)$; however, we found a positive significant correlation between the $\mathrm{mP} / \mathrm{Ao}$ ratio and ejection fraction $(P=0.006)$, systolic pulmonary artery pressure $(P<0.0001)$, and mean pulmonary artery pressure $(P<0.0001)$. In contrast, the correlation was nonsignificant when the $\mathrm{mP} / \mathrm{Ao}$ ratio was compared with other parameters $(P>0.05)$, and a

\section{Introduction}

Pulmonary hypertension $(\mathrm{PH})$ is considered when the mean pulmonary artery pressure (mPAP) is more than $25 \mathrm{mmHg}$ while measured at rest, estimated by right cardiac catheterization. Pulmonary arterial hypertension is diagnosed in patients who have precapillary $\mathrm{PH}$, pulmonary vascular resistance more than three Wood units, and end-expiratory pulmonary artery wedge pressure less than $15 \mathrm{mmHg}$ [1].

Irrespective of its etiology, the diagnosis of pulmonary arterial hypertension is crucial because of its association with bad prognostic predictors [2]. Catheterization of the right side of the heart is considered the gold standard modality in diagnosing $\mathrm{PH}$, despite being an invasive technique with many drawbacks [3]. Doppler echocardiography is usually considered a noninvasive, commonly used measure that assesses systolic pulmonary artery pressure (sPAP). This technique could be inexact, especially in interstitial lung disease [4]. Computed tomography (CT) is frequently performed for patients with predicted PH. The structures of the pulmonary vessels and heart with CT were studied accurately as an indicator of elevated mPAP [5]. nonsignificant correlation was also found between systolic pulmonary artery pressure and duration of dyspnea $(P>0.05)$.

Conclusion This study has shown that combining CT and echocardiography in the diagnosis of pulmonary hypertension can be a reliable technique to measure mean pulmonary artery pressure than if any of both tests done separately.

Egypt J Bronchol 2019 13:743-746

(C) 2020 Egyptian Journal of Bronchology

Egyptian Journal of Bronchology 2019 13:743-746

Keywords: chest computed tomography, echocardiography, pulmonary hypertension

${ }^{a}$ Chest Diseases Hospitals, Egyptian Ministry of Health, Cairo, Egypt, ${ }^{b}$ Department of Cardiovascular Diseases, ${ }^{\mathrm{C}}$ Department of Chest Medicine, Faculty of Medicine, Fayoum University, Fayoum, ${ }^{\mathrm{d} D e p a r t m e n t ~ o f ~ C h e s t ~}$ Medicine, Faculty of Medicine, Helwan University, Cairo, Egypt

Correspondence to Fatmaalzahraa S. Abdalrazik, MD, Department of Chest Medicine, Faculty of Medicine, Helwan University, Ain Helwan, Helwan, Cairo 11795, Egypt. Tel: +20 122722 3565;

e-mails: fatemaalzahraa.saad@med.helwan.edu.eg,

fatemaalzhraa_saad@yahoo.com

Received: 18 June 2019 Accepted: 10 September 2019

Published: 21 January 2020

This study was designed to evaluate the feasibility of $\mathrm{CT}$ in diagnosing $\mathrm{PH}$, and comparing $\mathrm{CT}$ sensitivity to echocardiography and If Both tests combined together in diagnosing $\mathrm{PH}$.

\section{Participants and methods}

\section{Study design}

This study is a prospective research that included 30 inpatients from the Chest Department in Fayoum University Hospital and diagnosed with $\mathrm{PH}$ secondary to chest disease from September 2015 to February 2016.

Ethics approval was obtained from the Ethical Committee of the Faculty of Medicine, Fayoum University, and consent was obtained from the patients' relatives.

This is an open access journal, and articles are distributed under the terms of the Creative Commons Attribution-NonCommercial-ShareAlike 4.0 License, which allows others to remix, tweak, and build upon the work non-commercially, as long as appropriate credit is given and the new creations are licensed under the identical terms. 


\section{Patients}

All study cases were subjected to detailed assessment of medical history, full clinical examination, routine chemical and hematological blood tests, spirometry including forced vital capacity - forced expiratory volume in the $1 \mathrm{~s}$ - forced expiratory volume in the $1 \mathrm{~s} /$ forced vital capacity ratio, pulse oximetry, echocardiography, and CT chest.

\section{Inclusion criteria}

$\mathrm{PH}$ secondary to primary pulmonary disease.

A patient is considered to have $\mathrm{PH}$ when the pulmonary artery pressure by echocardiography is more than $25 \mathrm{mmHg}$ as measured by the Bernoulli equation [6].

\section{Analytical method \\ Echocardiography}

Transthoracic echo-Doppler was done using the Toshiba Apolio 300 Ultrasound System (Cannon Medical Systems Corporation, Ōtawara, Japan). Two-dimensional images were taken. The pericardium, left-side chamber, and right-side chamber sizes, valves, and function were assessed. The right ventricular size and function were measured. Tricuspid regurgitation was assessed. Systolic pressure of the right ventricle was measured using the modified Bernoulli equation (equals sPAP in case of absence of outflow obstruction of the right ventricle) [4]. Pulmonary artery systolic pressure $(\mathrm{PASP})=4$ (tricuspid jet velocity squared) + right atrial pressure.

\section{Computed tomography chest imaging}

CT chest was performed using the Toshiba Aquilion Prime 160 slice MDCT scanner (Cannon Medical Systems Corporation). All candidates were examined while lying supine, holding their breath in deep inspiration. Thirty patients underwent high-resolution CT with an intravenous contrast injection. The widest shortaxis dimension of the main pulmonary artery on axial cuts at the level of the main pulmonary artery bifurcation through the mediastinal cuts of CT. The main pulmonary artery cross-sectional area was also measured. The thoracic vertebra and the ascending aorta were measured at the widest shortaxis diameters in the same cut used to evaluate the main pulmonary artery. The mid anteroposterior diameter of the vertebra is rarely affected by osteophytes; thus, it was chosen as a suitable area to be evaluated.

\section{Statistical methods}

We used mean $\pm \mathrm{SD}$, median and range, or frequencies and percentages to describe data. Pearson's moment correlation equation was used for linear relations. $P$ values less than 0.05 were considered to be statistically significant. All statistical calculations were carried out using the computer program SPSS (SPSS Inc., Chicago, Illinois, USA) release 15 for Microsoft Windows (2006).

\section{Results}

This study included 30 patients, six males and 24 females; their age ranged from 13 to 78 years (mean \pm SD 46 \pm 19.2 ). Twenty-six (86.7\%) patients were nonsmokers and four were smokers (Table 1). 6.7\% of these patients had obstructive lung disease and 93.3\% had restrictive lung disease (most of our candidates were diagnosed with interstitial lung) (Table 2). The mean blood oxygen saturation of the 30 cases was $90.57 \pm 7.67$, ranging from 68 to 99 (Table 3).

By doppler echocardiography, the mean ejection fraction was $67.10 \pm 6.13$, ranging from 53 to 85 , the mean sPAP was $54.23 \pm 19.51$, ranging from 38 to 128 , and the mPAP was $35.39 \pm 11.99$, ranging from 25.2 to 80.1 (Table 4).

\begin{tabular}{lc}
\multicolumn{2}{l}{ Table 1 Descriptive characteristics of all study cases } \\
\hline Variables & Mean \pm SD (range) \\
\hline Age (years) & $46 \pm 19.2(13-78)$ \\
Sex $[N(\%)]$ & \\
$\quad$ Male & $6(20)$ \\
Female & $24(80)$ \\
Smoking & \\
Nonsmokers & $26(86.7)$ \\
Smokers & $4(13.3)$ \\
\hline
\end{tabular}

Table 2 Degree of airway limitation among study cases according to pulmonary function tests

\begin{tabular}{lc}
\hline Variables & $N(\%)$ \\
\hline Obstructive & $2(6.7)$ \\
Restrictive & $28(93.3)$ \\
\hline
\end{tabular}

Table 3 Oxygen saturation among the studied patients

\begin{tabular}{lcc}
\hline Variable & Mean \pm SD & Range \\
\hline Oxygen saturation & $90.57 \pm 7.67$ & $68-99$ \\
\hline
\end{tabular}

Table 4 Echocardiographic and computed tomography findings of all study participants

\begin{tabular}{lcc}
\hline Variables & Mean \pm SD & Range \\
\hline Ejection fraction & $67.10 \pm 6.13$ & $53-85$ \\
Systolic pulmonary artery pressure & $54.23 \pm 19.51$ & $38-128$ \\
Mean pulmonary artery pressure & $35.39 \pm 11.99$ & $25.2-80.1$ \\
Main pulmonary artery/aorta ratio & $1.19 \pm 0.29$ & $0.73-2.10$ \\
\hline
\end{tabular}


When the same population was assessed by CT chest with contrast, we found that the mean main pulmonary artery and aorta main pulmonary artery/aorta ratio $(\mathrm{mPa} / \mathrm{Ao})$ ratio was $1.19 \pm 0.29$, ranging from 0.73 to $2.10,23.3 \%$ of cases had lymphadenopathy, $10 \%$ showed hyperinflated chest with emphysema, 66.7\% had the ground glass pattern, $66.7 \%$ had bronchiectasis, $23.3 \%$ had the reticulonodular pattern, 60\% had honey combing, 53.3\% had a prominent pulmonary artery, and $16.7 \%$ were found to have pericardial effusion (Table 4).

Agreement between the $\mathrm{mPa} / \mathrm{Ao}$ ratio and sPAP was found to be significant. The $\mathrm{mPa} / \mathrm{Ao}$ ratio and sPAP agreed that 21/30 (70\%) of the participants had $\mathrm{PH}$ and $3 / 30(10 \%)$ of the patients did not have $\mathrm{PH}$, with total agreement of 24/30 (80\%), Cohen's $\kappa=0.392$ and $P=0.019$ (Table 5).

In this study, we found a significant correlation between the $\mathrm{mPa} / \mathrm{Ao}$ ratio and the study parameters: we found a negative correlation of statistical significance between the $\mathrm{mP} / \mathrm{Ao}$ ratio and oxygen saturation $(P=0.001)$, whereas there was a positive correlation of statistical significance between the $\mathrm{mP} /$ Ao ratio and ejection fraction $(P=0.006)$, sPAP $(P<0.0001)$, and mPAP $(P<0.0001)$. However, our results showed that the correlation of the $\mathrm{mP} /$ Ao ratio with the other variables $(P>0.05)$, and the correlation between sPAP and duration of dyspnea $(P>0.05)$ were not different (Table 6).
Devaraj et al. [7] illustrated in their study that the diameter of the ascending aorta to the cross-sectional area of the main pulmonary artery is correlated equally with mPAP. Also, they concluded that combining both $\mathrm{CT}$ and echocardiography in $\mathrm{PH}$ can represent mPAP than each test separately.

Tan et al. [8] reported that the CT-determined mean pulmonary artery diameter plays an excellent diagnostic role in detecting $\mathrm{PH}$ in advanced lung disease patients.

A study carried out in 2014 by Lick et al. [9] included 127 patients who underwent computed tomography pulmonary angiography (CTPA) and echocardiography within $48 \mathrm{~h}$ of each other. They found that left atrial sizes in CTPA and Doppler echocardiography are strongly correlated. Also, found that ration of $\mathrm{mPa} / \mathrm{Ao}$ measured by CTPA in patients with increased pulmonary artery pressure. These results were markedly different compared with those of patients with normal pulmonary artery pressure. The researchers found that left atrial size measured by CTPA and that measured by echocardiography are strongly correlated.

Li et al. [10] recruited 85 patients with chronic chest diseases and performed both CT chest and right heart catheterization (RHC). The mPAP, PASP, and pulmonary arterial diastolic pressure were assessed

Table 5 Agreement between the main pulmonary artery/aorta ratio and systolic pulmonary artery pressure

\begin{tabular}{|c|c|c|c|c|}
\hline & \multicolumn{2}{|c|}{ Main pulmonary artery/aorta ratio } & \multirow[t]{2}{*}{ Cohen's $\kappa$} & \multirow[t]{2}{*}{$P$ value } \\
\hline & Pulmonary hypertension & Normal & & \\
\hline \multicolumn{5}{|c|}{ Systolic pulmonary artery pressure } \\
\hline Pulmonary hypertension & 21 & 5 & 0.392 & $0.019^{*}$ \\
\hline Normal & 1 & 3 & & \\
\hline
\end{tabular}

Bold and $\left({ }^{*}\right)$ means this value of statistical significance.

Table 6 Correlation between main pulmonary artery/aorta ratio, systolic pulmonary artery pressure ratio, and study parameters

\begin{tabular}{lc}
\hline & \multicolumn{1}{c}{ Main pulmonary artery/aorta ratio } \\
\cline { 2 - 2 } & \multicolumn{1}{c}{$P$ value } \\
\hline Age & 0.036 \\
Respiratory rate & 0.062 \\
Heart rate & 0.321 \\
Forced vital capacity & -0.066 \\
Forced expiratory volume in the 1 s & -0.168 \\
Forced expiratory volume in the 1s/forced vital capacity ratio & -0.073 \\
Oxygen saturation & -0.576 \\
Ejection fraction & 0.084 \\
Systolic pulmonary artery pressure & 0.490 \\
Mean pulmonary artery pressure & 0.374 \\
Systolic pulmonary artery pressure (duration of dyspnea) & 0.862 \\
\hline
\end{tabular}

*Means theses values of statistical significance. 
during RHC. Diameters of the main pulmonary artery, descending aorta, and ascending aorta, Cobb angle, diameters of left ventricle, and diameters of right ventricle, and diameters of left ventricle were estimated in CT. The mean values of CT-expected measures and RHC measures were statistically nondifferent.

In contrast to our finding, Iyer et al. [11], carried out a study that included 60 cases. They were evaluated by CT chest and echocardiography. The study concluded that the CT scan is more accurate than echocardiography in diagnosing resting pulmonary artery pressure in patients with severe chronic obstructive pulmonary disease (COPD).

A meta-analysis study that included 29 researches collected by Janda et al. [12] found that Doppler echocardiography is a reliable, noninvasive technique for assessing PASP, but because of some limitations, RHC should be performed during diagnosis and follow-up of $\mathrm{PH}$.

The limitations of this study were its cross-sectional nature and the fact that the study population was not homogenous with underlying lung disease. Also, despite almost equal numbers of candidates with interstitial lung disease and pulmonary vascular disease, special conditions, such as emphysema, were underrepresented.

Although noninvasive tools, such as echocardiography, help to assess PASP, this technique is usually problematic in COPD patients because of hyperinflation and difficult acoustic windows. It is important to note that all measurements are performed at rest.

The study authors recommend further investigation to compare the combined measurement of CT and echocardiography with RHC in measuring PASP.

\section{Conclusion}

This study has proven the synergistic effect of combining of $\mathrm{CT}$ and echocardiography in $\mathrm{PH}$ together is a more reliable technique in measuring mPAP than if any of both tests done alone.

\section{Financial support and sponsorship \\ Nil.}

\section{Conflicts of interest}

There are no conflicts of interest.

\section{References}

1 Hoeper MM, Pletz MW, Golpon H, Welte T. Prognostic value of blood gas analyses in patients with idiopathic pulmonary arterial hypertension. Eur Respir J 2007; 29:944-950.

2 Coghlan JG, Handler C. Connective tissue associated pulmonary arterial hypertension. Lupus 2006; 15:138-142.

3 McGoon M, Gutterman D, Steen V, Barst R, McCrory DC, Fortin TA, Loyd JE. Screening, early detection, and diagnosis of pulmonary arterial hypertension: ACCP evidence-based clinical practice guidelines. Chest 2004; 126:14S-34S

4 Arcasoy SM, Christie JD, Ferrari VA, Sutton MS, Zisman DA, Blumenthal $\mathrm{NP}$, et al. Echocardiographic assessment of pulmonary hypertension in patients with advanced lung disease. Am J Respir Crit Care Med 2003; 167:735-740.

5 Devaraj A, Wells AU, Meister MG, Corte TJ, Hansell DM. The effect of diffuse pulmonary fibrosis on the reliability of $\mathrm{CT}$ signs of pulmonary hypertension. Radiology 2008; 249:1042-1049.

6 Abbas AE, Fortuin FD, Schiller NB, Appleton CP, Moreno CA, Lester SJ. Echocardiographic determination of mean pulmonary artery pressure. Am J Cardiol 2003; 92:1373-1376.

7 Devaraj A, Wells AU, Meister MG, Corte TJ, Wort SJ, Hansell DM. Detection of pulmonary hypertension with multidetector CT and echocardiography alone and in combination. Radiology 2010; 254:609-616.

8 Tan RT, Kuzo R, Goodman LR, Siegel R, Haasler GR, Presberg KW. Utility of $C T$ scan evaluation for predicting pulmonary hypertension in patients with parenchymal lung disease. Chest 1998; 113:1250-1256.

9 Lick A, Danrad R, Smith D, Aiello D, Lammi M. Use of chest computed tomography angiogram as a predictor of diastolic dysfunction and pulmonary hypertension. Chest 2014; 146:578A.

10 Li M, Wang S, Lin W, Li J, Wang C, Chen H, et al. Cardiovascular parameters of chest CT scan in estimating pulmonary arterial pressure in patients with pulmonary hypertension. Clin Respir J 2018; 12:572-579.

11 lyer AS, Wells JM, Vishin S, Bhatt SP, Wille KM, Dransfield MT. CT scanmeasured pulmonary artery to aorta ratio and echocardiography for detecting pulmonary hypertension in severe COPD. Chest 2014; 145:824-832.

12 Janda S, Shahidi N, Gin K, Swiston J. Diagnostic accuracy of echocardiography for pulmonary hypertension: a systematic review and meta-analysis. Heart 2011; 97:612-622. 